\title{
El pipeño: historia de un vino típico del sur del Valle Central de Chile
}

\author{
The Pipeño: Story of a typical wine Southern Central Valley of Chile \\ Pablo Lacoste $^{1 *}$, Amalia Castro ${ }^{2}$, Félix Briones ${ }^{3}$, Fernando Mujica ${ }^{4}$
}

\begin{abstract}
RESUMEN
Se estudia la historia del pipeño, vino típico del centro-sur de Chile. Se trata de un vino elaborado a partir de Uva País, Moscatel de Alejandría y otras variedades criollas. Debe su nombre a las "pipas", barriles de roble chileno, que se comenzaron a usar en el siglo XVIII. Se trata de vinos elaborados con métodos artesanales, con profundo arraigo en las capas populares y campesinas de Chile. Durante mucho tiempo fue valorado negativamente por los enólogos y especialistas. Pero en los últimos años se ha comenzado a descubrir a partir de su identidad, su historia y su arraigo social.
\end{abstract}

Palabras clave: pipeño, vinos chilenos, industria del vino.

\begin{abstract}
This article studies the history of Pipeño, typical wine of south-central Chile. This is a wine made from grapes Country, Muscat of Alexandria and other landraces. It owes its name to the "pipes" Chilean oak barrels, which were first used in the eighteenth century. These are wines made from traditional methods, with deep roots in folk and peasant layers of Chile. For a long time was negatively valued by wine experts and specialists. But in recent years it has begun to discover from their identity, history and social roots.

Key words: pipeño, chilean wine, wine industry.
\end{abstract}

\section{Introducción}

El pipeño es un vino chileno, nacido en el siglo XVIII, dentro de un contexto mayor en el que surgieron también otros productos típicos, como el vino Asoleado de Cauquenes y Concepción, el queso curado de oveja llamado "Queso de Chanco", y los jamones de Chiloé, entre otros. Lo notable es que estos productos han tendido a desaparecer o deformarse. El jamón de Chiloé, famoso en la mesa del virrey del Perú en Lima, ya no tiene prácticamente vigencia; lo mismo ocurre con el vino Asoleado, desaparecido de los mercados. Más triste es la historia del queso de Chanco, que de un producto de alta calidad, elaborado a partir de leche de oveja, cuidadosamente curado, se ha degradado en una caricatura, por medio de la cual, grandes empresas nacionales e internacionales se han apropiado del prestigio de su nombre, destruyendo su calidad e identidad (Lacoste et al., 2014).

A diferencia de los otros productos típicos, el pipeño ha logrado mantenerse vivo y vigente hasta hoy. En efecto, el pipeño se ha convertido en un fenómeno notable dentro de Chile. Hasta hace pocas décadas era un vino marginal, propio de campesinos pobres, elaborado a partir de uvas criollas y conservado en barricas de roble chileno, llamadas pipas. Para las élites, era un vino menor, de escaso interés. Los grupos dirigentes del país y las corrientes principales de la enología nacional se han focalizado principalmente en las variedades de uva francesa (Pszczólkowski, 2013, 2014, 2015). Hasta ahora, las variedades criollas, los métodos artesanales y los vinos típicos han ocupado un espacio muy menor en la investigación académica, reflejo del papel subalterno de estos productos en la vida social y económica.

\footnotetext{
Universidad de Santiago de Chile, USACH. Santiago, Chile.

Universidad Finis Terrae. Santiago, Chile.

Universidad del Bío Bío. Chillán, Chile.

4 Escuela Nacional de Sommelier. Santiago, Chile.

* Autor por correspondencia: pablo.lacoste@usach.cl
}

Fecha de Recepción: 12 Enero, 2015.

Fecha de Aceptación: 14 Mayo, 2015. 
En los últimos años, esta tendencia comenzó a revertirse. La coctelería dio un primer paso al crear, a partir del pipeño, un trago de gran popularidad en Chile: el "terremoto", bebida elaborada a partir de este vino, helado de piña y fernet u otro bitter, edulcorante o destilado. Según las tradiciones orales, este cóctel surgió en oportunidad del terremoto de 1985, en algún restaurant tradicional de Santiago. Desde allí se difundió al resto del país, con gran aceptación entre los jóvenes.

El pipeño se mantiene vigente entre las cocinerías tradicionales, lugares que preservan el patrimonio culinario del país (Carstens y Soto, 2011). Además de vender el terremoto, también se promocionan otros tragos como la réplica (solo un vaso corto de terremoto) y el chichón (mezcla de chicha y pipeño). Muchas de estas picadas han hecho honor a este vino y han bautizado sus tiendas con el nombre del mosto o con el del recipiente donde se conserva. Conocidas, entre el mundo de las picadas populares, son el "Pipeño de Franklin", "Las Pipas de Einstein", "Las Pipas de Macul", "Las Pipas de Serrano", entre otros.

A ello se suma la valoración del pipeño como vino propio de la cultura nacional. Es notable el éxito comercial del pipeño promovido por los enólogos franceses Louis-Antoine Luyt y David Marcel, quienes, en la segunda década del siglo XXI, comenzaron a posicionarlo nuevamente en los mercados centrales del vino chileno. Cada uno de ellos se interesó por estos vinos y buscó la manera de reivindicarlo. El reconocimiento del mercado los premió con precios de entre 10 y 15 dólares la botella. En restaurantes, el vino pipeño se vende hasta 30 dólares la botella actualmente en Santiago de Chile. Además, gracias a la aceptación y la buena crítica por parte de los periodistas especializados en ámbitos vitivinícolas, y a la exposición de este vino en vitrinas del mundo de la restauración y de las ferias de especialidad como el "Chancho Deslenguado", el pipeño ocupa un espacio importante en el mercado agroalimentario, alcanzando buenas puntuaciones entre los críticos del vino. De esta manera, los pipeños, encabezados por Maitía, Tipaume, Cacique Maravilla y Louis-Antoine Luyt, se consolidan en el escenario vitivinícola nacional. El vino Aupa de Maitía fue galardonado con el título de vino revelación del 2014 y los pipeños de Manuel Moraga, Cacique Maravilla cosecha 2012 y Burdeos Pipeño cosecha 2013, obtuvieron, respectivamente, 92 y 94 puntos en la guía Descorchados (Tapia, 2014).
La persistencia del pipeño contrasta con otros productos típicos chilenos que, tras una destacada trayectoria en los siglos XVIII y XIX, desde la guerra del Pacífico han tendido a desaparecer. Dentro de este patrón general, el pipeño surge como un vino particular porque ha logrado mantenerse vivo y ello requiere una explicación.

El objetivo del presente artículo es aportar al conocimiento de la historia del Pipeño en Chile. Se trata de conocer y explicar los orígenes de este producto y la configuración de su identidad. Se espera aportar así al fortalecimiento de la identidad del pipeño, como base y punto de partida para su futuro desarrollo como vino típico de Chile.

Las referencias parciales de la literatura especializada en la historia del vino chileno trazan algunos antecedentes para conocer este producto. Pero han dejado muchas preguntas abiertas. Por un lado, conviene identificar qué uvas se utilizaban para elaborar estos productos. Gay (1855), Reyes Coca (2003) y Del Pozo (2014) los asocian con las uvas criollas, pero conviene definir con mayor claridad el concepto. También es importante determinar el área geográfica de estos productos. Reyes Coca afirma que el pipeño se elaboraba en el valle del Itata, pero es conveniente identificar el área con más precisión. Queda pendiente sistematizar la información disponible, enriquecerla con nuevas fuentes y establecer con mayor precisión la historia, identidad y ubicación geográfica de estas bebidas, objetos del presente artículo.

\section{Materiales y Métodos}

Para despejar estas incógnitas, es necesario utilizar el método propio de la historia (heurístico crítico) y compulsar los corpus documentales que permitan conocer la trayectoria histórica del pipeño en Chile. En primer lugar, se examinan los inventarios de bienes, testamentos y demás registros notariales y judiciales referidos al mundo de los viticultores en Chile, durante los siglos XVIII y XIX; estos documentos se conservan en el Archivo Nacional de Santiago y permite conocer el origen del uso de las pipas, recipiente que sirvió de base para el nombre del Pipeño. El segundo corpus lo constituyen los relatos campesinos, conservados en la Colección Fucoa de la Biblioteca Nacional; a partir de ellos se pueden conocer las prácticas de consumo de pipeño en la sociedad tradicional chilena. 


\section{De la pipa española al vino pipeño de Chile}

El pipeño debe su nombre al recipiente donde se conservaba: la pipa. La pipa era un barril de madera empleado en España y desde allí, en el siglo XVIII, llegó al reino de Chile, para asentarse por largo tiempo en el Valle Central. Así como el pisco adoptó su nombre, según algunas versiones, del recipiente en el cual se almacenaba, algo parecido ocurrió con el pipeño. Por lo tanto, la historia de este nombre se remonta a la introducción del recipiente.

El concepto de "pipa" ya se usaba en España a fines de la Edad Media. Según el primer diccionario en español, se definía como pipa "la civeta para vino". Luego se agrega que debe su nombre a la "espita que es a modo de teta que bebiendo por ella se chupa" (Covarrubias, 1611). Con el correr del tiempo el concepto evolucionó y, un siglo más tarde, el diccionario de autoridades entraba una nueva definición de pipa: "El tonel o candiota que sirve para transportar o guardar el vino" (RAE, 1737: 280). Esta definición tendió a consolidarse, como se reflejó en la edición del diccionario oficial de español de mediados del siglo XIX y fines del XX (RAE, 1852;1991).

La pipa ingresó de España a Chile en el segundo tercio del siglo XVIII, por Mendoza, la capital de la provincia de Cuyo del reino de Chile. El registro más antiguo corresponde al testamento de Juan de Godoy (1744), el que poseía siete pipas españolas con sus cinchos de fierro. En Mendoza y San Juan, las pipas se incorporaron rápidamente para transportar el vino. En efecto, los vinos cuyanos tenían sus mercados en Buenos Aires, mil kilómetros al este, y el transporte se realizaba en carretas por las suaves planicies pampeanas. En la segunda mitad del siglo XVIII se verificó el gradual proceso de sustitución de las botijas de greda por las pipas de madera como principal recipiente para transportar el vino de los lugares de producción (Cuyo) a los centros de consumo (Buenos Aires). En la década de 1770 se completó este proceso: a partir de entonces, las pipas y barriles se impusieron definitivamente como recipientes de conservación y transportes de los vinos de Mendoza y San Juan (Lacoste, 2007).

El rol de la pipa en la industria del vino fue muy diferente al otro lado de la cordillera. En Chile cisandino, las características del terreno no permitían el transporte del vino en carretas por largas distancias. Las fuertes pendientes de la cordillera de los Andes y la cordillera de la Costa, sumada a los torrentosos ríos de montaña, constituyeron un paisaje muy diferente al de las suaves planicies pampeanas: no hubo caminos carreteros en Chile colonial, con la sola excepción de la ruta de Santiago a Valparaíso, construida por los ingenieros de don Ambrosio O'Higgins a fines del siglo XVIII. Por lo tanto, el transporte se realizaba casi exclusivamente a lomo de mula, para lo que el recipiente más adecuado era el odre de cuero y no la pipa de madera.

La tríada conceptual de tinajas de greda, arrieros y odres de cuero fue la base del sistema de almacenamiento y transporte del vino en Chile, desde la llegada de los españoles, a mediados del siglo XVI, hasta la modernización de mediados del siglo XIX. Se trata de tres objetos emblemáticos que dominaron los paisajes del vino en Chile durante tres siglos. Las características del terreno chileno, con sus montañas y ríos, no eran compatibles con las carretas y con las pipas como envase para el transporte.

Impedida de servir como recipiente para transportar el vino, en Chile, la pipa se utilizó para conservarlo dentro de las bodegas, almacenes y pulperías. A partir de la segunda mitad del siglo XVIII, la pipa comenzó a formar parte del paisaje de las viñas y bodegas chilenas. Lentamente, estos recipientes de madera comenzaron a convivir con las tinajas tradicionales. No hubo una sustitución de un objeto por el otro; simplemente se amplió el sistema, con la incorporación de un nuevo recipiente, sin perder vigencia el anterior. Las tinajas chilenas se mantuvieron vigentes en la industria del vino hasta la segunda mitad del siglo XIX.

La difusión de las pipas en Chile se vio facilitada por la acción de los toneleros locales que desarrollaron las técnicas para fabricarlas a partir de las maderas disponibles. Los toneleros se dedicaron a fabricar pipas con madera de alerce en Santiago o de raulí (roble chileno) en Concepción (Gay, 1855).

La evidencia documental muestra que las primeras pipas se comenzaron a usar en la zona sur del Valle Central, en particular en las inmediaciones del valle del Itata. Concretamente, uno de los registros más antiguos corresponde a la Hacienda Cucha Cucha, propiedad de la Compañía de Jesús. En efecto, con motivo de la expulsión de esta orden religiosa, al levantarse los inventarios de bienes de las temporalidades se detectó, precisamente, "una pipa con sus arcos de fierro". ${ }^{1}$ 
Las pipas mostraron sus ventajas debido a su menor peso y mayor transportabilidad que las tinajas. Evidentemente, la madera resultaba más práctica para mover que la greda, sobre todo para objetos de grandes tamaños. Como resultado, estos recipientes se comenzaron a difundir por el reino de Chile. En Santiago, don Agustín del Castillo era viticultor de un viñedo de 37.700 cepas, incluyendo uva país, uva de Italia y moscateles. En sus bodegas tenía "cuatro pipas europeas de 14 arrobas de buque, con sus arcos de fierro, bien tratados, a $\$ 16$ cada una". ${ }^{2}$ Poco después, en una hacienda de San Felipe se registró una pipa con cinchos de fierro, de $8 \frac{1}{2}$ arrobas de capacidad, valuada en $\$ 12 .{ }^{3}$ En el mismo siglo XVIII, en la Hacienda de Apoquindo, en Santiago de Chile se registró "una pipa de madera con fajas de lo mismo, con buque de más de cinco arrobas, algo servida (tasada), en dos pesos y cuatro reales". ${ }^{4}$

Los documentos demuestran que en la segunda mitad del siglo XVIII se difundieron las pipas en Chile. Se hallaban en la zona central y sur, de San Felipe y Santiago hasta el Itata, pero no en el norte (no se registraron en el corregimiento de Coquimbo). Las pipas eran recipientes tamaño variable, de entre cinco y quince arrobas de capacidad; era un equipamiento de alto costo, pues se tasaban a un valor de entre 10 y 15 reales por arroba.

En la primera mitad del siglo XIX, el uso de las pipas se hizo cada vez más frecuente en la región y bajaron los precios. En cierta forma, se produjo la estandarización de este recipiente para la conservación del vino en las bodegas chilenas. En Santiago, don Marcelo Amaya tenía una pipa vacía valuada en ocho reales. ${ }^{5}$ Agustín Díaz tenía siete pipas de entre doce y catorce arrobas de capacidad (valuadas a $\$ 7$ cada una) y otras cinco pipas de cinco a siete arrobas de buque (tasadas a $\$ 4$ cada una). Las siete grandes se tasaron a $\$ 49$ y las cinco medianas en $\$ 20 .{ }^{6}$ La bodega del convento de San Agustín tenía tres pipas. ${ }^{7}$ Don Francisco Prats, propietario de una viña de 11.000 plantas, tenía en su bodega una pipa de 15 arrobas y tres pipas de 78 arrobas; en ambos casos se tasaron a 5 reales por arroba, llegando a $\$ 9$ con dos reales la primera y a $\$ 48$ con seis reales las tres restantes. ${ }^{8}$ En la misma capital, Francisco Hidalgo tenía siete pipas de 8 arrobas de capacidad cada una y otras 2 pipas que contenían 24 arrobas de licor, valuado a 4 reales por arroba. ${ }^{9}$ Don Mateo Besoin también tenía este equipamiento en su bodega, donde las pipas de madera tenían en conjunto 44 arrobas de capacidad. ${ }^{10}$ Cien kilómetros al nordeste de la capital, en San Felipe, se registró poco después una pipa de 24 arrobas de capacidad, valuada a tres reales por arroba. ${ }^{11}$ En líneas generales, se nota que hubo una expansión de las pipas y una caída de los precios. En la primera mitad del siglo XIX las pipas se hicieron cada vez más comunes en las viñas chilenas, y el precio cayó a la mitad: si en la centuria anterior se tasaban entre 10 y 15 reales por arroba, en la primera mitad del XIX bajaron a cerca de tres reales por arroba. La pipa se hizo cada vez más popular.

A mediados del siglo XIX, la pipa estaba consolidada como el recipiente de conservación del vino en las pequeñas viñas artesanales chilenas. Las grandes empresas se apartaron de este modelo, con la importación desde Francia de las grandes cubas de roble francés. En cambio, las viñas artesanales consolidaron la tradición de la pipa, recipiente que mantuvieron vigente a lo largo de todo el siglo XX. Sobre la base de esta tradición se generaron las condiciones para el surgimiento del vino pipeño.

El concepto de "vino pipeño" surgió en forma paralela al de "uva país", como respuesta identitaria frente al avance del proceso de afrancesamiento de la vitivinicultura de Chile. En efecto, hasta mediados del siglo XIX, estas denominaciones no existían. Las viñas chilenas cultivaban principalmente la llamada uva misión en California, negra corriente en Perú y negra en Chile y Argentina. En la década de 1840 comenzó a llegar la uva francesa a Chile y hacia 1913 ya había 20.000 hectáreas de estas variedades frente a 50.000 de uva país. Las cepas francesas se hallaban en las grandes viñas, ubicadas entre Santiago y Talca, mientras que las uvas criollas se ubicaban principalmente en los pequeños minifundios artesanales, entre el Maule y el Itata. Las variedades francesas cambiaron el paisaje del viñedo en Chile y también los usos y costumbres de hablar y hacer. Si las cepas de cabernet, merlot, syrah, malbec y carmenere se denominaban "uva francesa", la tradicional uva negra requería un nuevo nombre para distinguirse; por eso se comenzó a llamar uva país en Chile y criolla chica en Argentina. Lo mismo ocurrió con el "vino pipeño". A partir de la segunda mitad del siglo XIX, de las cepas francesas se comenzó a elaborar un vino llamado comúnmente "burdeos" en Chile. El vino que provenía de las uvas criollas era llamado simplemente vino o mosto. Faltaba un nombre más 
específico. Surgió entonces el nombre de pipeño, porque este era el recipiente más difundido en las viñas del sur del Valle Central de Chile, donde no penetraron las grandes fábricas de vino con sus cubas de roble francés. Quedó entonces la tradición del vino pipeño, para denominar al que se elaboraba con uva país, se pisaba con pie de hombre, se fermentaba en lagares abiertos y se conservaba en pipas de roble chileno (Reyes Coca, 2003).

Aunque la vinificación era artesanal, la producción aumentó y los pipeños vendimiados "a pata y chala limpia", tenían excelentes ventas, en Coelemu, Ninhue, Quirihue, Portezuelo, Cerro Negro, Quillón, Ñipas, etc., tanto dentro como hacia afuera de los lugares de producción. En la provincia de Nuble se consolidó un polo de producción y consumo de vinos pipeños, lo mismo que en el secano costero e interior de la región de Maule. En la actualidad, en estos territorios de Coelemu, Quillón, Guarilihue, Quirihue, Cerro Negro y Las Raíces, aledaños a la cuenca del Itata, en la Región del Biobío, la viña forma parte importante del paisaje cultural agroalimentario y continúa arraigada a las tradiciones de la vida campesina (Mariángel y Moya, 2013; Mariángel y Vega, 2013).

También se hacía mención al acompañamiento del vino con las comidas típicas chilenas, por ejemplo, vino blanco de Coelemu, vino tinto y vino blanco de San Carlos; los caldos de Nipas, Guarilihue y Cerro Negro y los vinos de Guarilihue y San Carlitos; se habla de vino tinto, del vino tinto de Coelemu, y, por último, los vinos pipeños, pipeño de Portezuelo y vinos de la zona (Alcalde, 1972).

Cabe mencionar un oficio único que existía relacionado con los envases de vino: los limpiadores de pipas. El relato acerca de este oficio es el siguiente: "Nolberto Iglesias tiene contratado a Juan de Dios Andrade, que apenas se empina sobre el metro y es el encargado de la hazaña. Debe subir una escalera y meterse en el interior de la pipa y provisto de un escobillón y un traje protector para lavarla por dentro y sacarle 'la madre del vino', que es la borra acumulada. Trabajo peligroso porque muchas veces las emanaciones del alcohol reseco producen vómitos y desmayos. Juan de Dios Andrade después de tomarse su correspondiente caña y la aspirina para 'evitar el resfriado', se despide como un pasajero que va a emprender un largo viaje. Un ayudante le alumbra y le descuelga una ampolleta: 'Chico, ¿estái vivo?' La voz de Juan de Dios retumba con eco: ‘¡Sí, oh!’ A la salida le pagan su trabajo con otra caña, otra aspirina y diez lucas" (Alcalde, 1972).

El desarrollo del pipeño se encuentra integrado en la historia social, económica y cultural de Chile desde el periodo colonial hasta la actualidad, particularmente en las capas populares de la población, sobre todo en las zonas rurales.

\section{Los tecnócratas afrancesados y la demonización del pipeño}

La valoración y el desarrollo del pipeño se vieron fuertemente afectados por la campaña de desprestigio que pusieron en marcha los tecnócratas europeos y sus seguidores chilenos, que tendieron a sobrevalorar el estilo francés de vinos y a minimizar los vinos típicos chilenos.

Este movimiento comenzó a mediados del siglo XIX, liderado por tecnócratas europeos que, a partir de la posición de prestigio que ocupaban en Chile, impusieron una visión muy proclive a valorar el estilo francés como único paradigma válido en la industria del vino. Referentes como Claudio Gay, Julio Menadier y René Le Feuvre construyeron un discurso que tendía a valorar todos los elementos franceses como los únicos válidos, y a la vez, negar los méritos que la viticultura chilena había construido durante tres siglos.

En el discurso de los tecnócratas solo tenían valor enológico las cepas francesas; en cambio las uvas criollas (Uva País, Moscatel de Austria, Pedro Giménez, Torontel) no merecían ninguna consideración. Lo mismo ocurría con los medios de elaboración: para estos tecnócratas, solo tenían significado las técnicas y equipamientos europeos, particularmente franceses, mientras que los métodos artesanales chilenos carecían absolutamente de interés. Dentro de esta corriente se valoraban las barricas de roble francés, a la vez que se negaba valor a las pipas de roble chileno. Esta tendencia fue continuada después por los agrónomos, enólogos y referentes chilenos, comenzando por Manuel Rojas, autor del más importante manual de enología y vinificación de Chile, reeditado recurrentemente entre 1891 y 1950. En los últimos años, esta mirada ha sido renovada por nuevos autores, como Alvarado Moore, ingeniero agrónomo muy consultado por los especialistas del mundo vitivinícola. Sus palabras profundizan la tendencia a estigmatizar este vino típico:

"El pipeño es un vino bruto, es decir, sin clarificación, filtración ni decantación alguna. Se trata 
de un vino que tiene todas las impurezas, llamadas borras o heces. (...) "El expendio de vino pipeño debería estar absolutamente prohibido. Conviene saber que todas las impurezas descritas, maceradas con el alcohol y ácidos naturales del vino, desarrollan una serie de compuestos químicos muy complejos que son desconocidos para nuestro organismo, al margen de que la estabilidad biológica del producto es más que sospechosa". El autor respalda sus comentarios en una investigación que realizó en distintas partes del país sobre la cirrosis. "Los resultados preliminares fueron muy alarmantes: la más alta incidencia se daba en las comunas vitivinícolas apartadas, en las que, virtualmente, todo el vino consumido era el dichoso pipeño" (Alvarado Moore, 1997).

El discurso de Alvarado Moore es la culminación de la tendencia a minimizar el valor de los productos típicos chilenos, iniciada a mediados del siglo XIX por Claudio Gay, Julio Menadier y René Le Feuvre, y continuada después por los enólogos chilenos como Manuel Rojas. Fue una corriente poderosa, hegemónica dentro del pensamiento vitivinícola de Chile y América Latina en general, desarrollado en el marco de un proceso de intoxicación identitaria y colonialismo consumista. Esta corriente tendió a demonizar, debilitar y destruir muchos productos típicos chilenos de gran valor, como el queso de Chanco, el vino asoleado de Cauquenes y el pisco entre otros. Como se examina en profundidad en otros textos (Lacoste et al., 2014).

Es importante señalar que el discurso de los tecnócratas afrancesados atacó a todos los productos típicos chilenos, incluyendo el queso de Chanco, el vino asoleado de Cauquenes, entre otros. Las élites chilenas se manifestaron muy vulnerables a ese discurso, y tendieron a abandonar el consumo de estos productos. Como resultado, los productos típicos chilenos de alta calidad y precio, destinados al mercado de alto poder adquisitivo, perdieron sus clientelas. Después de la guerra del Pacífico, los consumidores comenzaron a sustituir los productos típicos chilenos por productos importados o bien, por productos nacionales que eran copia de aquellos, como el vino "Burdeos de Talca", el "Champagne de San Felipe" y el "Queso Brie de Quillota". Abandonados por su mercado objetivo, los productos típicos chilenos dirigidos a las élites, entraron en decadencia hasta desaparecer, como en el caso del asoleado y el queso de Chanco.

La situación del pipeño fue distinta porque no era un producto para las élites, sino para el pueblo.
Y el pueblo resistió mejor que las élites el discurso de los tecnócratas, salvando así un producto típico chileno.

\section{Pipeño en la vida campesina}

A pesar de la posición hegemónica del discurso de los tecnócratas, el pipeño luchó durante un siglo para mantenerse vivo en Chile, apoyado por los pequeños productores artesanales y los consumidores del pueblo chileno, que no se dejaron someter por las corrientes principales de la industria.

El pipeño ha sido, a lo largo de la historia de Chile, parte importante de la vida social en los sectores populares del Valle Central. Es el reflejo del esfuerzo de los pequeños propietarios, que han mantenido encendida la llama de la tradición y la cultura de la vid y el vino en torno a paisajes cargados de cepa País y Moscateles, proceso que la antropología moderna define como endoculturación. La endoculturación "es una experiencia de aprendizaje parcialmente consciente y parcialmente inconsciente a través de la cual la generación de más edad incita, induce y obliga a la generación más joven a adoptar los modos tradicionales de pensar y comportarse. (...) Cada generación es programada no solo para replicar la conducta de la generación anterior, sino también para premiar la conducta que se adecue a las pautas de su propia experiencia de endoculturación y castigar, o al menos no premiar, la conducta que se desvía de éstas" (Marvin Harris (2013). Así se explica, en términos antropológicos, la lucha desesperada que sostienen los viñateros del pipeño por perpetuar su tradición. En un espacio paralelo al que construyeron las grandes marcas mediante la publicidad y el marketing, el pipeño mantuvo su influencia en la vida cotidiana, en los encuentros sociales y en las reuniones familiares. Se integraron en el corazón mismo de la vida de las personas. Y si bien en las zonas urbanas perdieron protagonismo por el control de las cadenas de distribución ejercido celosamente por las grandes firmas, en las zonas rurales lograron mantener su presencia.

Los relatos campesinos de la Colección Fucoa, atesorada en la Biblioteca Nacional de Santiago, constituyen una interesante fuente para reconocer la presencia del pipeño en la vida social del Valle Central de Chile. En efecto, esta colección se formó de manera relativamente espontánea, a partir de la convocatoria anual del Ministerio de Agricultura. 
La colección Fucoa reúne diez mil cuentos originales donados desde 1992 por la Fundación de Comunicaciones del Agro (Fucoa) del Ministerio de Agricultura. Estos relatos surgieron como resultado de los concursos de cuentos e historias campesinas realizados anualmente por este organismo. Después de más de dos décadas de funcionamiento, se ha creado un fondo documental que rescata los usos y costumbres de las zonas rurales de Chile. Por lo general se trata de relatos de gente de la tercera edad $\mathrm{y}$, en algunos casos, los autores refieren historias aprendidas de labios de sus mayores, al calor de la chimenea en noches de invierno. Estos relatos no tienen una fecha precisa, pero en buena medida, representan usos y costumbres de la primera mitad del siglo XX, con un margen de proyección anterior $\mathrm{y}$ posterior a esa fecha.

El pipeño es mencionado en cuatro oportunidades en los cuentos de la colección FUCOA ${ }^{12}$. Aparece en estos relatos dentro de un mismo patrón sociocultural: es parte del ambiente de fiesta y celebración que gustan construir los campesinos. Alrededor del pipeño se crea el ambiente de sociabilidad, de amores, de encuentros y desencuentros, de dramas y sucesos memorables. Cuando la cosecha era fructífera, las bodegas se llenaban de frutos que se convertirían en espumosos vinos. ${ }^{13}$ En el relato, esta bebida sirve como parte del escenario dentro del que se desarrollan los sucesos que merecen la pena recordar y relatar.

El pipeño surge como elemento de cohesión y socialización. Es parte de la estructura de la vida social; ofrece el marco dentro del que se desenvuelven historias que se reconocen como valiosas e interesantes para la comunidad de referencia. A la vez, representa un tramo decisivo dentro de los ciclos anuales de vida agrícola de trabajo, cultivo y cosecha.

En el ámbito de la fiesta campesina, el alcohol y comida juegan roles fundamentales. El consumo del pipeño representa el momento de la celebración por la buena cosecha. Luego, esa tradición de celebrar la fecundidad del año agrícola se proyectó a los otros motivos de fiesta, tanto por motivos familiares (matrimonios, bautizos, cumpleaños) como en las celebraciones cívicas. Para las fiestas del 18 de septiembre (aniversario de la independencia de Chile), los hombres tomaban el pipeño tinto ${ }^{14}$. Las sabrosas comidas preparadas para estas celebraciones se acompañaban de pipeños con olor a "roble viejo" ${ }^{15}$. Tanto era así, que en estas fiestas, en que cocinaban las mujeres, los hombres "trocaban penas por alegrías"16.

Esta bebida se reconocía como parte indispensable del ambiente de fiesta. Sin ella, simplemente, no había celebración. El espacio de encuentro se construía, precisamente, a partir de la posibilidad de compartir este producto. Además, el pipeño no solo se bebía; también tenía una función de maridaje con la gastronomía. Servía para acompañar las comidas más sabrosas y condimentadas, como la empanada y la cazuela. También se valoraba para elaborar pescados y mariscos. En un relato se ponderaba los "inolvidables camarones cocidos en tres hervores de pipeño blanco con un cacho e' cabra"17. Si los varones se lucían con sus buenos vinos, las mujeres se destacaban con la gastronomía y el maridaje.

Posteriormente Pablo de Rokha, en su Epopeya de comidas y bebidas de Chile, menciona puntualmente el pipeño: "no comamos la ostra en ese ambiente, en el que relumbran y descuellan los congrios-caldillos o flamea la bandera de un pipeño incomparable". Pero la referencia más llamativa es la de Raúl Rivero, en su poema "Quilmo", en el que el pipeño forma parte de una escena muy melancólica: "Doña Cleofilda me invitó a comer/ un domingo de invierno. (...)/ En el momento trascendente y clásico/ de escanciar ambas copas/ se apagaron las luces./ Dejó de hablar la radio./ Se produjo un silencio./ Algo pasó en el aire./ Me tomé el vino en sombras./ Un vino de Chillán, pipeño, claro,/ con sabor a nostalgias o a naranjas".

El mundo popular y campesino logró mantener viva la tradición del pipeño como producto típico de Chile. Le dio la fuerza necesaria para hacer frente a la estigmatización de los tecnócratas. Los chilenos modestos, sobre todo del campo, no cedieron a las corrientes ideológicas que, desde el poder, trataron de destruir los productos típicos chilenos, como hicieron con el queso de Chanco (el mejor queso del Cono Sur en los siglos XVIII y XIX, elaborado con leche de oveja) y el vino Asoleado de Cauquenes (el mejor de Chile en el siglo XIX). A diferencia de estos productos, el pipeño logró mantenerse con vida, precisamente, apoyado por las capas populares chilenas.

\section{Conclusiones}

El pipeño es un vino con profunda tradición histórica en Chile. Sus orígenes se remontan a la segunda mitad del siglo XVIII, cuando se difundió la 
pipa como recipiente para conservación de los vinos en el reino de Chile. Desde entonces, se ha mantenido como un vino típico de la zona sur del Valle Central, sobre todo entre los ríos Maule y Biobío.

Consistente con sus orígenes coloniales, el pipeño se elabora a partir de las uvas que se cultivaban en el siglo XVIII en Chile: Moscatel de Alejandría, para los blancos, y Uva País, en el caso de los rosados y tintos. También se emplean variedades derivadas de las dos anteriores, como Torontel (Moscatel Amarillo), Moscatel de Austria y Moscatel Rosado. El pipeño es un vino artesanal, elaborado con métodos tradicionales. No se emplean en su elaboración equipamiento ni instalaciones sofisticadas. Se elabora en forma sencilla, sin barrica de roble francés ni guarda en botellas. Se debe emplear la pipa de roble chileno (raulí).

El pipeño nació en el marco general de los productos típicos chilenos de los siglos XVIII y XIX, como el jamón de Chiloé, el queso de Chanco y el vino Asoleado de Cauquenes y Concepción. Todos estos productos fueron parte de la historia social, económica y cultural del país. Fueron elaborados en Chile con materias primas chilenas y mano de obra chilena para el mercado nacional, principalmente. La diferencia entre ellos se hallaba en los segmentos de mercado a los que iba dirigido: mientras que los jamones de Chiloé, los quesos de Chanco y los vinos Asoleados de Cauquenes eran productos de alto costo y elevado precio, se dirigían a un mercado de alto poder adquisitivo (élites). En cambio el vino pipeño se colocaba en los mercados populares.

A partir del último tercio del siglo XIX, todos los productos típicos chilenos fueron cuestionados y estigmatizados por los tecnócratas europeos y sus seguidores nacionales. Desde sus posiciones de poder, estos tecnócratas construyeron un discurso demonizador que debilitó estos productos y propició su sustitución por productos importados y sus copias nacionales (Champagne de San Felipe o queso Brie de Quillota). Las élites fueron muy permeables al discurso de los tecnócratas, y tendieron a cambiar sus hábitos de consumo. Como resultado, los productos típicos chilenos perdieron sus mercados y desaparecieron.

A diferencia de los productos típicos de élites, el pipeño logró mantenerse vivo en Chile, sostenido por los consumidores de extracción popular y campesina. El Chile profundo se reveló más resistente ante el discurso de los tecnócratas, y mantuvo su cultura y valoración de los productos típicos. El pipeño se siguió elaborando, valorando y consumiendo, muchas veces en la clandestinidad. Se comercializaba para los clientes que querían un "vino de la casa" en restaurantes, en las cocinerías, en las picadas y en los clandestinos. De esta forma se conservó el mercado interno, local. Se mantuvo viva la tradición de la viticultura más antigua de Chile, y sobre todo, se logró asegurar la persistencia del pequeño viticultor artesanal que, con sus pequeñas viñas y su modesto equipamiento, ha sido capaz de defender su derecho a mantener su identidad y su estilo de vida. De esta manera logró mantener vivo el pipeño.

En los últimos años se produjo la revaloración del pipeño, a partir del renovado interés por los productos identitarios y los valores del patrimonio agroalimentario nacional. En realidad, este resurgimiento es parte de un proceso mayor, signado por la valoración de los productos con identidad, arraigados a un territorio determinado (Coello, 2008). En el Cono Sur, estas corrientes se reflejan también en el creciente interés por productos como el pisco en Perú (Huertas, 2004 y 2012) y Chile (Cortés, 2005; Lacoste, 2013 y 2014). En esta corriente se ubica también la reivindicación de la Uva País para elaborar vinos espumantes, como han logrado con éxito Miguel Torres en Curicó y Capel en Coquimbo. En las últimas décadas, la producción de pipeño se ha consolidado principalmente en el secano costero e interior del Maule y en el valle del Itata. El pipeño, a partir de 2013 se comenzó a fraccionar en botellas de vidrio y con originales marcas y etiquetas para venderlo en las grandes ciudades; como resultado, el pipeño llegó a los comercios especializados (Mundo del Vino) y a las mesas de los más selectos restaurantes de Santiago. La historia está de nuevo presente.

\section{Agradecimiento}

Los autores agradecen al proyecto Fondecyt 1130096. 


\section{Literatura Citada}

Alcalde, A.

1972. Comidas y bebidas de Chile. Santiago, Editora Nacional Quimantu Ltda., 93 pp.

Alvarado Moore, R.

1997. El mundo del vino. Crónicas de un enólogo. Santiago, Turismo y Comunicaciones S.A., 175 pp.

Castro, A.

2014. Curar penas, alegrar el alma. Alcohol y vino en los relatos campesinos chilenos. Revista Iberoamericana de Viticultura, Agroindustria y Ruralidad (RIVAR) 1 (1): 57-74.

Carstens, C.; Soto, R.

2011. Chancho y Pipeño. Un recorrido por diez cocinerías tradicionales chilenas de Santiago. Piel de Gallina, Santiago, $60 \mathrm{pp}$.

Coello, C.

2008. El Sistema Jurídico de las Denominaciones de Origen. Las Bases Históricas y Administrativas del Derecho Vitivinícola Español. Sevilla, Junta de Andalucía, Instituto Andaluz de Administración Pública. Conserjería de Justicia y Administración Pública, 1460 pp.

Cortés, $\mathrm{H}$.

2005. El origen, producción y comercio del pisco chileno, 1546-1931. Universum, 20 (2): 42-81.

Covarrubias, S. de.

1995. Tesoro de la lengua castellana o española. Edición original: 1611. Edición moderna consultada: Madrid, Editorial Castalia, 1047 pp.

Del Pozo, J.

2014. Historia del vino chileno. Desde la época colonial hasta Gay, C. hoy. Santiago, LOM Ediciones, $306 \mathrm{pp}$.

1973. Historia física y política de Chile. Tomo II: Agricultura. Santiago, Museo de Historia Natural, 1855. Edición moderna consultada: Santiago, Icira, 443 pp.

Harris, M.

2013. Antropología cultural. Editorial Alianza, Madrid, 655 pp.

Huertas, L.

2004. Historia de la producción de vinos y piscos en el Perú. Universum, 19 (2): 44-61.

Huertas, L.

2012. Cronología de la producción del vino y del Pisco (Perú 1548-2010). Lima: Editorial Universitaria, 393 pp.

Lacoste, P.; Soto, N.; Jiménez, D.

2014. Genesis and identity of Chanco cheese (Chile 17501860) Contribution to the study of Appellations of Origin in Latin America. Cien. Inv. Agr. 41 (3): 317-325.

Lacoste, P.; Jiménez, D.; Briones, F.; Castro, A.; Rendón, B.; Jeffs, J.

2014. Burdeos de Talca y Champagne de Mendoza: Denominaciones de Origen y contaminación identitaria de vinos en Argentina y Chile. Mundo Agrario, 15 (28): $1-25$.

Lacoste, P.; Briones, F.; Jiménez, D.; Rendón, B.

2014. La Denominación de Origen Pisco en Chile: algunos problemas nacionales e internacionales. Idesia, 32 (2): 47-56.

Lacoste, P.; Jiménez, D.; Castro, A.; Rendón, B.; Soto, N.

2013. A binationalAppellation of Origin: Pisco in Chile and Peru. Chilean Journal of Agricultural Research, 73 (4): 107-114.

Lacoste, $\mathrm{P}$.

2007. La hacienda vitivinícola (Mendoza y San Juan, siglo XVIII). Universum, 22 (1): 152-185.

Mariángel, P.; Moya, R.

2013. Tiempos de fogón. Las cocinas campesinas de la cuenca del Itata, Región del Biobío. Ediciones CET SUR, Tomé, 117.

Mariángel, P.; Vega, M.

2013. Entre gredas y adobes. Una aproximación a los oficios tradicionales y su valor patrimonial en Coelemu y Quillón. Ediciones CET SUR, Tomé, 105.

Pszczólkowski, P.

2014. "Terroir" y "Climats": ¿realidad o quimera? Revista Iberoamericana de Viticultura, Agroindustria y Ruralidad (RIVAR), 1 (1): 13-19.

Pszczólkowski, Ph.

2015. Sauvignon Blanc, Cabernet-Sauvignon y Carmenère, cepas claves de la viticultura actual de Chile. Revista Iberoamericana de Viticultura, Agroindustria y Ruralidad (RIVAR), 2 (4): 1-16.

Pszczólkowski, Ph.

2013. Carmenère, mayoría de edad: 1994-2012. Estudios Avanzados, 20: 137-154.

Real Academia Española.

2002. Diccionario de Autoridades. Tomo II, 1737. Edición Facsímil: Madrid, Gredos, 696 pp.

Real Academia Española.

1852. Diccionario de la lengua castellana. 10 edición. Madrid, Imprenta Nacional, $731 \mathrm{pp}$.

Real Academia Española.

1991. Diccionario de la lengua española. 21 edición. Madrid, Espasa Calpe, II tomos, 2133 pp.

Reyes Coca, M.A.

2013. Del pipeño con gusto a borra. La Discusión de Chillán. Sección Opinión. Jueves 14 de febrero 2013.

Reyes Coca, M.A.

2003. Los vinos moscatel y país, de los cerros de Ñuble: de pipeños y fama. Tiempo y Espacio,11-12 (9): 281-288.

Tapia, $\mathrm{P}$.

2014. Guía Descorchados 2014. Guía de vinos de Chile. Santiago, Editorial Planeta, 465 pp.

\section{Notas}

1 Inventario de bienes de la Hacienda Cucha Cucha, 26 de octubre de 1767. Archivo Nacional, Fondo Jesuitas de Chile, pieza 3, folio $199 \mathrm{v}$.
2 Tasación del sitio de don Agustín del Castillo, Santiago, 8 de marzo de 1785. AN, Fondo Judiciales de Santiago, legajo 226 , pieza 7 , foja $14 \mathrm{v}$. 
3 Inventario de bienes de Pedro Antonio Pérez, San Felipe, 3 de octubre de 1787. AN, Fondo Judiciales de San Felipe, legajo 42 , pieza 18 , foja 43 .

4 Inventario de la Hacienda de Apoquindo, propiedad de los herederos del finado José Antonio Grez. Santiago de Chile, 2 de mayo de 1795. AN, Fondo Judiciales de Santiago, pieza 9, folio $19 \mathrm{v}$.

5 Tasación de bienes de don Marcelo Amaya, Santiago 18 de febrero de 1812. AN, Fondo Judiciales de Santiago, legajo 45, pieza 5 , foja 47.

6 Inventario de bienes de Agustín Díaz, Santiago de Chile, 16 de junio de 1827. AN, Fondo Judiciales de Santiago, volumen 304, pieza 9 , foja 27.

7 Tasación de la quinta de los Agustinos, Santiago, 20 de febrero de 1826. AN, Fondo Judiciales de Santiago, pieza 9, foja 1v.

8 Tasación de bienes de don Francisco Prats, Santiago, 10 de julio de 1837. AN, Fondo Judiciales de Santiago, Legajo 177, pieza 4 , foja $1 \mathrm{v}$.

9 Partición de bienes de Francisco Hidalgo, Santiago de Chile, 1846. AN, Fondo Judiciales de Santiago, volumen 496, pieza 11 , fojas $5 \mathrm{v}$ y 17.
10 Inventario de bienes del finado don Mateo Besoin, Santiago, 23 de noviembre de 1848. AN, Fondo Judiciales de Santiago, volumen 150 , pieza 10 , foja $3 \mathrm{v}$.

11 Cobro de pesos por deuda impaga. San Felipe, 26 de junio de 1849. AN, Fondo Judiciales de San Felipe, Legajo 50, Pieza 16, foja 27v.

12 Fundación de Comunicaciones, Capacitación y Cultura del Agro.

13 Gastón Pérez Verdugo. El hombre que fabricaba ríos. Rancagua, VI Región, 2007, Carpeta 200, cuento 10.204.

14 María Magdalena Rubio Sepúlveda "Tradicionales Chilenas" Huilco, Melipilla, RM, 2007, Carpeta 204, cuento 10.377 . Autora nacida en 1926.

15 Eliana Silva Lizana. La guitarrera. Chillán, 2002, Carpeta 73, cuento 2932.

16 Eliana Silva Lizana. La guitarrera. Chillán, 2002, Carpeta 73, cuento 2932.

17 Luis Samuel Campos Pinto. "Fiesta de los tres camarones". San Pedro de la Paz, 2007, Carpeta 199, cuento 10.126. 